\title{
Anxiety association with suicidal ideation or behaviour in individuals aged $18-49$ years
}

\author{
Ieva Briede $^{1}$ and Velga Sudraba ${ }^{2}$ \\ ${ }^{1}$ Riga Centre of Psychiatry and Addiction Disorders, Riga, Latvia \\ ${ }^{2}$ Rịga Stradinsš University, Riga, Latvia
}

\begin{abstract}
Anxiety and suicide - closely related concepts, the understanding of which would contribute to the overall mental and physical health of society, and which is the basis for the successful development of any country. The primary aim of the study is to identify anxiety indicators for individuals with suicide ideation or behaviour. Secondary - find out anxiety association with suicidal ideation or behaviour in individuals aged 18-49 years. For research purposes, a questionnaire created by the authors and Spielberger's State-Trait Anxiety self-evaluation questionnaire were used which helped to obtain the data about 165 people aged 18-49 years who have had suicidal ideation or behaviour, or attempts. The results of the study reveal that the more frequent manifestations of suicide are suicidal ideation rather than suicidal behaviour or attempts. The study produced results that confirm a positive association between higher anxiety state and suicidal ideation as well as recurrence of thoughts i.e. the higher the anxiety state the more often and repeatedly people think about suicide. The same correlation can be observed between anxiety trait and suicidal thoughts and their recurrence.
\end{abstract}

Key words: suicide, anxiety, anxiety state, anxiety trait.

\section{Introduction}

Suicide as a serious public health problem requires attention but, unfortunately, suicide prevention and control is not an easy task. Research of the current situation shows that suicide prevention should be implemented through a complex set of activities ranging from providing the best possible conditions for upbringing children and youth to effective treatment of mental illnesses and risk control. Dissemination of relevant information and rising of general awareness are vital elements of suicide prevention programs.

In the European Union, Latvia is among the countries with the highest suicide rates Latvia takes the fourth place by suicide rate per 10,000 inhabitants (first three - Lithuania, Hungary and Slovenia) [3]. In Latvia 384 people in 2015, but 364 people in 2016, committed deliberate self-harm (suicide) [4]. In 2014, State Emergency Medical Service recorded 1,525 people who had attempted suicide and survived in the pre-hospital emergency phase. In 2014, the highest number of suicide attempts in Latvia was among population aged $20-34$ years. In 2014, the highest mortality rate due to suicide in Latvia was in the age group 35 - 49 years [5]. Every year a significant number of the population attempt suicide - data from international studies show that per one person who dies in suicide there are on average 20 people who attempt suicide [6]. Anxiety disorder is thought to increase the risk of suicidal ideation and attempts [7-13]. The primary aim of the study is to identify anxiety indicators in individuals with suicidal ideation or behaviour. Secondary - find out anxiety association 
with suicidal ideation or behaviour in individuals aged $18-49$ years, as suicide activity is most common in this age group. The following research tasks were set: create a socio demographic data survey and place it together with the Spielberger's State - Trait Anxiety survey on a website, inviting adults 18 to 49 years of age to complete them, and analyze the received data. Prior to conducting the study, permission was obtained from Riga Stradiņš University Ethics Committee to conduct the study.

\section{Methods}

\subsection{Participants in the study}

Study selection: available selection. On the website from February 20 to May 20, 2017, persons aged 18 - 49 years who have had suicidal ideation or who have attempted suicide were invited to complete 2 surveys. The survey was conducted at https://surveys.google.com, which was used to collect data, and e-mails were sent to the councils of various universities asking to forward them to students. Of the sent e-mails, 165 fully completed questionnaires were received which are analyzed below. All respondents were briefed on the nature of the study and gave informed consent by completing surveys.

\subsection{Set of instruments}

Two tools were used to obtain research data: a questionnaire developed by the authors for the assessment of suicidal ideation or behaviour and Spielberger's State-Trait Anxiety selfevaluation questionnaire. A questionnaire developed by the authors contains 13 questions, such as demographic data, which include questions about the respondent's age, gender, education, relationship, presence of children. Other questions related to the experience of respondents regarding suicidal ideation or behaviour, which include questions whether and how often there has been suicidal ideation, if there has been any suicidal behaviour, and whether someone close has committed suicide. Respondents were not asked if they were in the psychiatrist's records, receive medication, or have any medical diagnosis. A pilot study was conducted to test the questionnaire.

Spielberger's State-Trait Anxiety self-evaluation questionnaire (STAI Form Y - 1) [1] (adaptation and standardisation in Latvia: D. Škuškovnika [2]) consists of two parts. Each part contains 20 items: the first part determines the anxiety state of respondents (A - state), statements are related to the current situation; the second part determines anxiety as a personality trait (A - trait), these statements are related to general feelings. Each answer is evaluated on the Likert scale from 1 to 4 . The result can vary from 20 to 80 points. The sum of the points obtained in the test allows us to suggest low anxiety; 31 - 45 moderate anxiety, but over 46 - high anxiety [2].

\subsection{Data processing and analysis}

Statistical processing of the obtained data was performed with MS Excel software and SPSS 21 statistical program.

The following data processing methods were used:

- descriptive statistics;

- Kolmogorov - Smirnov normality test;

- Spearman Rank Correlation was used as the data did not correspond to normal distribution. 
Table 1. Distribution of respondents by socio - demographic data $(N=165)$.

\begin{tabular}{|l|l|c|r|}
\hline Socio-demographic characteristics & $\boldsymbol{n}$ & $\mathbf{\%}$ \\
\hline \multirow{3}{*}{ Gender } & Female & 124 & 75.2 \\
\cline { 2 - 4 } & Male & 41 & 24.8 \\
\hline \multirow{4}{*}{ Age } & $18-29$ & 152 & 92.1 \\
\cline { 2 - 4 } & $30-39$ & 11 & 6.7 \\
\cline { 2 - 4 } & $40-49$ & 2 & 1.2 \\
\hline \multirow{4}{*}{ Education } & Primary education & 5 & 3 \\
\cline { 2 - 4 } & Secondary education & 82 & 49.7 \\
\cline { 2 - 4 } & Higher education & 78 & 47.3 \\
\hline \multirow{3}{*}{ Children } & Single & 147 & 89.1 \\
\cline { 2 - 4 } & Married & 16 & 9.7 \\
\cline { 2 - 4 } & Widow/-er & 2 & 1.2 \\
\hline \multirow{5}{*}{ Live with } & No & 147 & 89.1 \\
\cline { 2 - 4 } & Yes & 18 & 10.9 \\
\hline & Parents & 57 & 34.5 \\
\cline { 2 - 4 } & Spouse/partner & 47 & 28.5 \\
\cline { 2 - 4 } & Alone & 37 & 22.4 \\
\cline { 2 - 4 } & Other & 24 & 14.6 \\
\hline
\end{tabular}

Verifying the reliability of the results, the internal consistency of the test was determined using Cronbach's alpha coefficient. Compared to Spielberger STAI - Y original sample figures (from 0.89 to 0.96 ) [1] and adapted sample figures (from 0.83 to 0.92 ) [2], in this study Cronbach's alpha coefficients for A - state and A - trait scales are accordingly 0.927 and 0.881 , which indicate a high degree of coherence.

\section{Results}

165 people aged 18 - 49 years who have attempted suicide or who have had suicidal ideation were interviewed, $75.2 \%$ (124) of the respondents were women (see table 1). The results of the survey show a present day trend that most people under the age of 30 live freely $-89.1 \%$ (147) of respondents have stated that they are not married and there are as many of them who do not have children.

Answering the question "How often have respondents had suicidal ideation?" almost half $(41.8 \%)$ say that they have had suicidal ideation a couple of times in life, but 6 respondents have noted that they have suicidal ideation a few times a week and that they have suicidal ideation every day (see Table 2).

Almost a fifth of respondents admit that they had experienced suicidal ideation during the last year. Less than $10 \%$ of respondents noted that they had had suicidal ideation during the last month or last week. About $20 \%(n=32)$ of respondents admit that they have had suicidal behaviour: 22 of them noted that they have had such behaviour at some point in their lives, but 6 respondents - during the last year, but 3 - during the last week.

Of the respondents, $40.6 \%(n=67)$ indicate that there have been suicide cases or attempts among their close people. For the question - who has committed suicide or attempted suicide in the lives of respondents - there was a choice of multiple answers, the percentage of each response is calculated according to its frequency which allows total percentage to exceed the usual $100 \%$. Of these 67 respondents, $45 \%$ or 30 individuals noted that they were friends while 7 respondents indicate the mother and 5 respondents - the father.

According to Kolmogorov - Smirnov normality test A - state and A - trait levels correspond to normal distribution $(p>0.05)$ [14], therefore the average arithmetic $(\mathrm{M})$ and standard deviation for the anxiety state and anxiety trait were calculated (see Table 3 ). As the 
Table 2. Suicidal ideation and behaviour of respondents $(N=165)$.

\begin{tabular}{|c|c|c|c|}
\hline Survey questions & Multiple choice answers & $n$ & $\%$ \\
\hline \multirow[t]{6}{*}{ How often have respondents had suicidal ideation? } & Once in life & 52 & 31.5 \\
\hline & A few times in life & 69 & 41.8 \\
\hline & A few times a year & 18 & 10.9 \\
\hline & A few times a month & 14 & 8.5 \\
\hline & A few times a week & 6 & 3.6 \\
\hline & Every day & 6 & 3.6 \\
\hline \multirow[t]{2}{*}{ Have respondents had repeated suicidal ideation? } & Yes & 92 & 55.8 \\
\hline & No & 73 & 44.2 \\
\hline \multirow[t]{6}{*}{ When did respondents last have suicidal ideation? } & Some time in life & 92 & 55.8 \\
\hline & During last 1 year & 30 & 18.2 \\
\hline & During last 1 month & 16 & 9.7 \\
\hline & During last 1 week & 14 & 8.5 \\
\hline & Yesterday & 3 & 1.8 \\
\hline & Today & 10 & 6.1 \\
\hline \multirow[t]{2}{*}{ Have respondents had suicidal behaviour? } & Yes & 32 & 19.4 \\
\hline & No & 133 & 80.6 \\
\hline \multirow{4}{*}{$\begin{array}{l}\text { When did respondents have suicidal behaviour? } \\
(n=32)\end{array}$} & Some time in life & 22 & 76.2 \\
\hline & During last 1 year & 6 & 14.3 \\
\hline & During last 1 month & 1 & 2.4 \\
\hline & During last 1 week & 3 & 7.1 \\
\hline \multirow{2}{*}{$\begin{array}{l}\text { Has someone in the family or among friends of } \\
\text { the respondents committed suicide or attempted } \\
\text { suicide? }\end{array}$} & Yes & 67 & 40.6 \\
\hline & No & 98 & 59.4 \\
\hline \multirow{5}{*}{$\begin{array}{l}\text { Who has committed suicide or attempted suicide } \\
\text { in the family or among friends of the respondents? } \\
(n=67)\end{array}$} & Mother & 7 & 10.4 \\
\hline & Father & 5 & 7.5 \\
\hline & One of the grandparents & 8 & 11.9 \\
\hline & Other relative & 29 & 43.3 \\
\hline & Any of friends & 30 & 44.8 \\
\hline
\end{tabular}

Table 3. Descriptive statistics (mean and standard deviation) of respondents' anxiety state and trait.

\begin{tabular}{|l|r|r|}
\hline Anxiety & $M$ & \multicolumn{1}{|c|}{$S D$} \\
\hline Anxiety State & 45 & 11.9 \\
\hline Anxiety Trait & 48 & 9.6 \\
\hline
\end{tabular}

aim of the study was to find out whether state and trait anxiety is associated with suicidal ideation or behaviour the respondents were not categorized by age or gender, data were analyzed in aggregate form, although the majority of respondents are under the age of 30 and they are women.

Figure 1 shows that most respondents $(63.1 \%, 104)$ have a high level of anxiety trait, while, accordingly, 39.4\% (65) and 48.5\% (80) respondents have high and average anxiety state.

Calculating correlations between socio-demographic data and suicidal ideation and behaviour, a statistically significant positive correlation between recurrent suicidal ideation and the possibility of suicidal behaviour has been identified $(r=0.283, p<0.001)$. There is a statistically significant negative correlation between having children and recurring suicidal ideation $(r=-0.197, p=0.011)$ and the fact that suicidal ideation has been before $(r=$ 


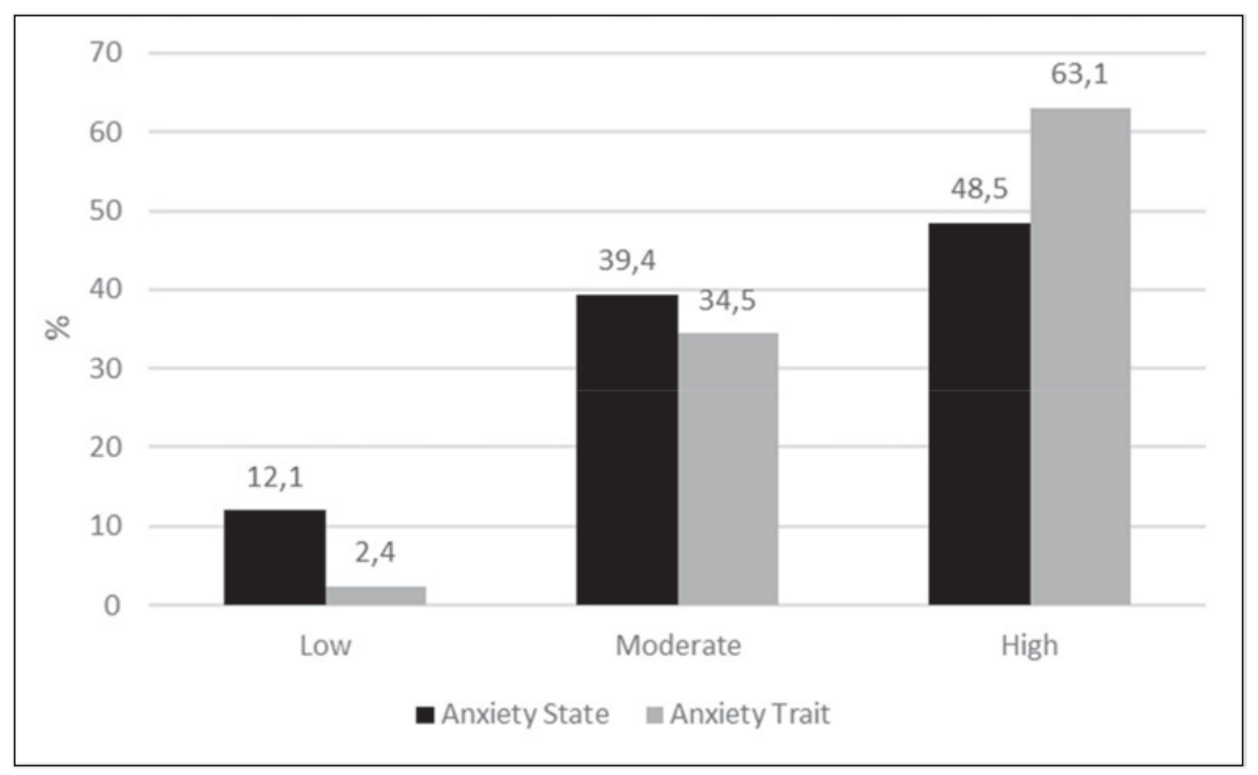

Fig. 1. Respondents' Anxiety State and Trait levels.

$-0.155, p=0.047)$. There is a statistically significant positive correlation between suicidal ideation and its recurrence $(r=0.599, p<0.001)$. There is a statistically significant positive correlation between the frequency of suicidal ideation and the fact that it has occurred very recently $(r=0.687, p<0.001)$.

There is a statistically significant negative correlation between a higher A- state and being married $(r=-0.154, p=0.048)$, and having children $(r=-0.167, p=0.032)$.

There is a statistically significant positive correlation between a higher $\mathrm{A}$ - state and the frequency of suicidal ideation $(r=0.538, p<0.001)$; suicidal ideation recurrence $(r=$ $0.480, p<0.001)$ and the time since suicidal ideation occurred $(r=0.518, p<0.001)$, and previous suicidal behaviour $(r=0.176, p=0.024)$.

There is a statistically significant positive correlation between a higher A - trait and the frequency of suicidal ideation $(r=0.517, p<0.001)$; suicidal ideation recurrence $(r=$ $0.448, p<0.001)$ and the time since suicidal ideation occurred $(r=0.471, p<0.001)$, and previous suicidal behaviour $(r=0.173, p=0.026)$.

\section{Discussion}

Suicidal ideation and behaviour are also topical issues in Latvia. Although only those who have suicidal ideation appear in the survey, the high activity of respondents indicates that suicide is topical, if not at the level of performance then at least at the level of ideation. Most respondents are under the age of 29 , which may be due both to the fact that the survey link was initially sent to various university councils asking them to send it out to students and to the increased use of the web by young people. However, this is consistent with other studies showing that suicide attempts are more common among young people up to 34 years but suicide mortality rates are higher in those younger than 49 . Analysis of the survey data shows that there is a statistically significant positive correlation between the higher A - state and the frequency of suicidal ideation, as well as suicidal ideation recurrence, that is, the higher the 
anxiety state the higher the possibility that a person has suicidal ideation more frequently. The findings of this study confirm the conclusion of a study [15] already carried out in 2012, that situational anxiety can be a significant risk factor in cases of suicidal ideation. Similarly, various studies have concluded that anxiety disorders increase the risk of suicidal ideation and attempts [7-13].

The results of the study show that there is a statistically significant negative correlation between having children and suicidal ideation recurrence, in other words, people with children have a lower risk of committing suicide, which suggests that responsibility for others forces to give up real self - harm. Data from the World Health Organization also show that people who do not have children are more likely to commit suicide.

Oxford scientists discovered a similar correlation in the situation of anxiety state and people living in marriage - they have found that those who are married are less anxious than those who are not married [17]. The results of this study also show this correlation - there is a statistically significant negative correlation between a higher A - state and a married person. In other words - a person who is married has a lower risk of being with a high $\mathrm{A}$ - state.

There is a close connection between the thoughts of an individual and the environment, which can promote or, on the contrary, suppress the realization of such thoughts in practice. It is very important for every individual to have a supportive family, friends or just the possibility to receive support - such an aspect significantly improves the quality of life, thus reducing the risk of becoming suicidal ideation carrier or suicidal behaviour performer.

There are several limitations to the study. Firstly, aggregate data processing of all respondents should be mentioned, with no distinction between age groups and genders, without comparing them. It should also be noted that an age limit of 49 was set and a survey link was sent to universities, which determined that this study had a dominance of young individuals, not necessarily showing the real situation. Another limitation is the use of a website that allows responding individuals who may be dishonest and may not meet the inclusion criteria. Respondents were also not asked if they were in the psychiatrist's records, receive any medication or other assistance to reduce anxiety, thereby the results of anxiety should be interpreted with caution. However, it cannot be denied that the level of anxiety reported by respondents is high, suggesting that individuals in general need help to reduce it.

\section{Conclusions}

Analysis of research data confirms that there is a statistically significant positive correlation between a higher anxiety state and suicidal ideation. In addition, increased anxiety over a long time increases the risk of suicide.

Research data show that suicidal ideation reoccurs but the positive fact is that this suicidal ideation is not practically implemented. Thus, it can be concluded that often such ideation has appeared only under the influence of a more difficult moment of life and not as a real solution to the difficulties. However, the more often such suicidal ideation overtakes a person the more likely is that the person can get to real performance. A positive trait is that the results of the study show that life in marriage and having children reduce the risk of suicidal ideation or behaviour. Of course, it must be immediately taken into account that society has become more open and marriages as well as children are being moved further in the future, i.e. more and more people are starting a family after reaching other goals, for example, good career, education, etc., thus the risk - reducing aspects of suicide move away.

The authors of the study emphasize the significance of the results obtained in the study to detect anxiety state and anxiety trait. A large proportion of respondents in the survey have high anxiety levels indicating that a person may have difficulty in dealing with many 
anxiety-provoking situations, and suicidal ideation appears to be the way out. This suggests the importance of early identification and early assistance of such individuals, for example, possibility to get support from specialists, anonymous telephone hotline, etc. It is often important for people to realize that this help is provided anonymously and that no one will find out about the specific problems. It is therefore very important to educate society in general, so that public would not stigmatize people, who recognize their problems concerning suicide. The more educated the public will be in those matters the healthier thoughts will live in it, and it will be possible to help most people suffering from suicidal ideation.

A broader study would be needed, both with a larger age range and with dividing separate groups of respondents, for example, who have only had suicidal ideation or who have also committed self-harming activities, or - those who had a parent committing suicide, etc., as well as focusing on those respondents who are or are not receiving psychiatric or psychotherapy help.

\section{References}

[1] C.D. Spielberger, Manual for the State-Trait Anxiety Inventory (Form Y) (Palo Alto, CA, Consulting Psychologists Press, 1983)

[2] D. Skuškovnika, Trauksme latviešiem un Latvijā dz̄ivojošiem krieviem: promocijas darbs: specialitāte - sociālā psiholoìija. Rīga (2004)

[3] Eurostat Causes of death statistics. From: Eurostat. Available: http://ec.europa.eu/ eurostat/statistics-explained/index.php/Causes_of_death_statistics/lv (2013)

[4] CDPC data about mortality - 2016. From: Centre for Disease Prevention and Control. Available: https://www.spkc.gov.lv/upload/Veselibas\%20aprupes\% 20statistika/Statistikas\%20dati/2016/mirstiba_par_2016.doc

[5] CDPC data about mortality - 2015. From: Centre for Disease Prevention and Control. Available: https://www.spkc.gov.lv/upload/Veselibas\%20aprupes\%20statistika/ Statistikas\%20dati/mirstiba_par_2015.doc

[6] Mental health Suicide data. From: World Health Organization. Available: http://www.who.int/mental_health/prevention/suicide/suicideprevent/en/ (2013)

[7] M.A.Thibodeau, P.G. Welch, J. Sareen, and G. J. Asmundson, Depress Anxiety 10, 947-54 (2013)

[8] B. Park, S.Y. Kim, J.Y. Shin, R.W. Sanson-Fisher, D.W. Shin, J. Cho, J.H. Park, Suicidal ideation and suicide attempts in anxious or depressed family caregivers of patients with cancer: A nationwide survey in Korea. PLoS One 8(4), e60230 (2013)

[9] H. Chartrand, J. Sareen, M. Toews, J.M. Bolton, Depress Anxiety 29(3), 172-9 (2012)

[10] J. Nepon, S.L. Belik, J. Bolton, J. Sareen, Depress Anxiety 27(9), 791-798 (2010)

[11] G.J. Diefenbach, S.B. Woolley, J.W. Goethe, J Nerv. Ment. Dis. 197(2), 92-7 (2009)

[12] G.E. Simon, J. Savarino, Am. J. Psychiatry 164(7), 1029-1034 (2007)

[13] J. Sareen, B.J. Cox et al. Archives of General Psychiatry 62, 1249-1257 (2005)

[14] W.W. Daniel, Applied Nonparametric Statistics. 2nd ed., 319-330 (Boston, PWS-Kent, 1990)

[15] K.E. Schaefer, C. Esposito-Smythers and J.H. Riskind, J. Affect Disord. 143(1-3), 95101 (2012)

[16] World health statistics 2016: monitoring health for the SDGs, sustainable development goals. From: World Health Organization. Available: http://apps.who.int/iris/bitstream/10665/206498/1/9789241565264_eng.pdf?ua=1

[17] D. Semple, R. Smyth, Oxford Handbook of Psychiatry. 3rd ed., 351-392 (United Kingdom, Oxford University Press, 2013) 